\title{
The waistline of Indian men is expanding faster than women with general obesity and abdominal obesity reaching a epidemic in Indian subject with diabetes
}

\author{
Lalitha $\mathbf{R}^{1}$, Surekha B Shetty ${ }^{2}$, Anil Kumar $\mathbf{R}^{3}$ \\ ${ }^{1}$ Dr Lalitha R, Consultant Diabetologist, ${ }^{2}$ Dr Surekha B Shetty, Consultant Diabetologist, ${ }^{3}$ Dr Anil Kumar R, Consultant \\ Diabetologist, all authors are affiliated with Karnataka Institute of Endocrinology and Research, Bannerghatta Road, \\ $9^{\text {th }}$ block Jayanagar, Bangalore, India.
}

Address for Correspondence: Dr Lalitha R, Karnataka Institute of Endocrinology and Research, Bannerghatta Road, $9^{\text {th }}$ block Jayanagar, Bangalore, India. Email- drlalithashivaprakash@gmail.com

\begin{abstract}
Background \& Objectives: People with obesity and overweight are increasing in India. This study aimed at determining the prevalence of generalized and abdominal obesity in diabetics and comparison between genders. Methods: An observational study held at Diabetes centre, between 2013-2014. Classification of obesity was done using WHO and IDF criteria for BMI in Asians, while Waist Circumference and WHR per IDF criteria. WHO Asia Pacific guidelines were used to define overweight [body mass index (BMI) $\geq 23 \mathrm{~kg} / \mathrm{m}^{2}$ but $<25 \mathrm{~kg} / \mathrm{m}^{2}$, generalized obesity, BMI $\geq 25 \mathrm{~kg} / \mathrm{m}^{2}$ ), abdominal obesity, waist circumference $\geq 90 \mathrm{~cm}$ in men, $\geq 80 \mathrm{~cm}$ for women). 4504 subjects (men 2741 , women 1763 ) with diabetes aged $\geq$ of 25 were recruited. Results: The prevalence rates were 2, 13, $31 \& 54 \%$ women and 3, 23, 48, \& $26 \%$ men were lean, normal, overweight and obese respectively. Comparing the waist circumference between men and women with IDF criteria $65 \%$ men $(n=9235)$ and $89 \%(n=8175)$ have a WC above the normal. Waist hip ratio, identified higher prevalence rate in men $(89 \%)$ compared to women $(76 \%)$ and WHR was a sensitive index compared to WC. Interpretation \& Conclusions: Higher prevalence of abdominal obesity compared to general obesity in diabetic population affected both genders similarly. Both general and abdominal obesity prevalence are higher in women than men. Our study found that AO had a higher prevalence in men contrary to the belief that women have higher AO. Abdominal obesity is directly linked to increased morbidity.
\end{abstract}

Keywords: Abdominal Obesity; General Obesity; Diabetes; Indians, Waist Circumference.

\section{Introduction}

According to the World health Organisation (WHO) obesity has more than doubled and affects more than 1.9 billion adults aged 18 years and older were overweight. Of these over 600 million adults were obese based on WHO global estimates in 2014. Obesity is now affecting India in similar pattern to global presence. The projected prevalence of over weight increased from 2005 to 2015 as per WHO is $22 \%$ in men to $31 \%$, women $21 \%$ to $29 \%$ respectively $[1,2]$. Diabetes is already a huge burden on the health care system in India; in addition, obesity and overweight can multiply the health risks by increasing cardiovascular

Manuscript received $25^{\text {th }}$ September 2016

Reviewed: $10^{\text {th }}$ October 2016

Author Corrected: $20^{\text {th }}$ October 2016

Accepted for Publication $31^{\text {st }}$ October 2016 mortality, obstructive pulmonary disease, musculoskeletal disorders, hypertension, dyslipidaemia and cancers [3, 4]. Due to these increased risks obesity is considered as a disease in its own right. The risk for these disorders appears to start from a body mass index (BMI) of about $21 \mathrm{~kg} / \mathrm{m} 2$. Obesity is generally classified as generalized obesity (GO) and abdominal obesity (AO). Individuals with obesity have higher rates of mortality and morbidity compared to non-obese individuals. [3, 4].

India is the second most highly populated country in the world and is currently experiencing an astronomical epidemiological transition in relation to diabetes. Rapid development has driven a fast-growing epidemic of 
diabetes in India. Diabetes cases in age group (20-79) in 1000 s is $65,076.36$. Diabetes related deaths in age group $(20-79)$ is $1,065,053$. The Diabetes raw national prevalence is $8.56 \%$. Number of people with undiagnosed diabetes (20-79) in 1000s is 31,919.96 [5]. As India continues to undergo large-scale urbanisation and life expectancy rises, the diabetes prevalence is estimated to increase by $70 \%$ in the next two decades. Diabetes is increasingly affecting individuals in their most productive years. This will pose a challenge to governments working to improve the economic situation in our country. More than half of the deaths due to diabetes occur in people under 60 years of age and one quarter in people under 50 years of age.

Under nutrition due to poverty in the past, is being rapidly replaced by obesity associated with affluence [6]. Various studies from different regions of India have provided evidence of the rising prevalence of obesity [6-9]. We need to know our regional prevalence to tackle this issue and take health measures to halt the rapid progression.

\section{Material \& Methods}

This is a cross sectional study of type 2 diabetic subjects attending the outpatient clinic at Karnataka Institute of Diabetology, A total of 4504 individuals (2741 men and 1763 women) aged between $25-85$ years were selected who had a confirmed diagnosis for type 2 diabetes during the period 2013-2014. Individuals with Type 1 diabetes, and gestational diabetes were excluded from the study.

All subjects who participated underwent anthropometric measurements such as weight, height, hip and waist circumference. The study was approved by the Institutional Ethics Committee of the Karnataka Institute of Diabetology, and an informed consent was obtained from all the participants.

Anthropometric parameters were measured using standardized techniques [12]. Height (in centimetres) was measured using a stadiometer (SECA Model 214, Seca Gmbh Co Hamburg, Germany).

The individual was asked to stand upright without shoes with his/her back against the vertical back board, heels together and eyes directed forward. Weight (in kilograms) was measured with an electronic weighing scale (SECAModel 807, Seca Gmbh Co, Hamburg, Germany) that was kept on a firm horizontal flat surface. Subjects were asked to wear light clothing, and weight was recorded to the nearest $0.1 \mathrm{~kg}$. Body mass index (BMI) was calculated using the formula weight (kg) / height $(\mathrm{m})^{2}$. Waist circumference (WC) centimetres were measured using a non-stretchable measuring tape. WC was measured at the smallest horizontal girth between the costal margins and the iliac crest at the end of expiration. Hip measurement was done using a measuring tape at the widest part of the hips.

Definitions-Overweight was defined as a BMI $\geq 23$ $\mathrm{kg} / \mathrm{m} 2$ but $<25 \mathrm{~kg} / \mathrm{m} 2$ for both genders (based on the World Health Organization in Asians, Guidelines) with or without abdominal obesity (AO). [10]

Generalized obesity (GO) was defined as a BMI $\geq 25$ $\mathrm{kg} / \mathrm{m} 2$ for both genders (based on the World Health Organization in Asians) with or without abdominal obesity (AO). [10]

Abdominal obesity (AO) was defined as a waist circumference $(\mathrm{WC}) \geq 90 \mathrm{~cm}$ for men and $\geq 80 \mathrm{~cm}$ for women with or without GO [11].

Isolated generalized obesity (IGO) was defined as a $\mathrm{BMI} \geq 23 \mathrm{~kg} / \mathrm{m} 2$ with waist circumference of $<90 \mathrm{~cm}$ in men and $<80 \mathrm{~cm}$ in women. Isolated abdominal obesity (IAO) was defined as a waist circumference of $\geq$ $90 \mathrm{~cm}$ in men or $\geq 80 \mathrm{~cm}$ in women with a BMI $<23$ $\mathrm{kg} / \mathrm{m} 2$. WHR of $>0.9$ for men $>0.85$ for women.

Combined obesity (CO): Individuals with both $\mathrm{AO}$ and GO. Non-obese subjects: Individuals without GO or AO Diabetes was defined by a confirmed physician diagnosis of diabetes and current use of medications for diabetes (insulin or oral hypoglycaemic agents) and/or fulfilment of criteria laid down by the WHO Consultation Group Report, i.e. a Fasting Plasma Glucose $\geq 7 \mathrm{mmol} / \mathrm{l}(126 \mathrm{mg} / \mathrm{dl})$ and/or a $2 \mathrm{~h}$ post prandial plasma Glucose $\geq 12.2 \mathrm{mmol} / \mathrm{l}$ (200mg/dl) [12].

Statistical analysis- The data were gathered and managed on an excel spreadsheet. Data from a total of 4504 subjects with all anthropometric values were analysed. Mean and standard deviations summarized the continuous variables. The differences in the anthropometric parameters were compared.

A comparison was made between genders. Prevalence rates were calculated using the standard formulas. 


\section{Results}

In Table 1 we can see the total number of subjects of the selected study population and the total number of subjects with the averages is shown. We infer from the table that the study population is having GO, AO and CO.

\begin{tabular}{|c|c|c|}
\hline & WOMEN & MEN \\
\hline AVG HT & 153.22 & 167.22 \\
\hline AVG WEIGHT & 65.26 & 71.1 \\
\hline AVG BMI & 27.66 & 25.32 \\
\hline AVG W/H & 0.89 & 0.96 \\
\hline AVG WAIST & 91.2 & 92.13 \\
\hline AVG HIP & 101.15 & 94.95 \\
\hline TOTAL & 1763 & 2741 \\
\hline
\end{tabular}

General obesity as defined by BMI criteria was classified into lean, normal, over weight and obese based on values $<18.5,18.5-23,23.1-27.5$ and $>27.5$ respectively. Referring to figure 1 we can see the prevalence of general obesity in men and women. The prevalence rates for lean, normal, over weight and obese are $2 \%, 14 \%, 35 \%$ and $49 \%$ for women and $3 \%, 24 \%, 47 \%$ and $26 \%$ for men respectively. We notice that twofold women are obese compared to men. Two fold men are overweight than women. The prevalence rates for GO is $73 \%$ and $84 \%$ men and women respectively.

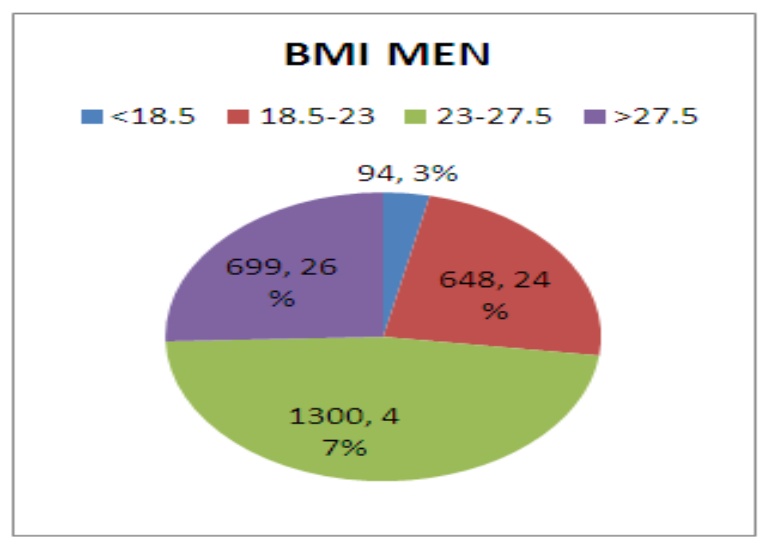

Figure-1

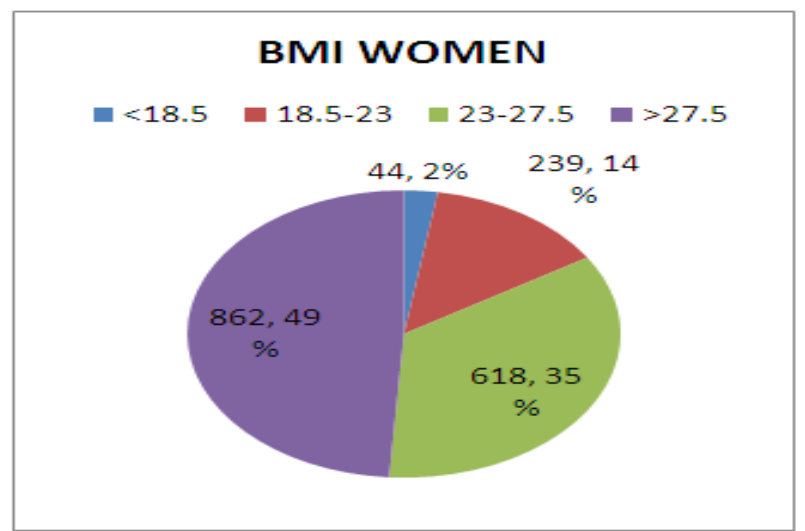

Figure-2

In figure 3and 4, comparing AO in men and women we note that 1646 men and1508 women have an abnormal waist circumference. Abnormal waist circumference was defined as $>80$ centimetres $(\mathrm{cms})$ for women and $>90 \mathrm{cms}$ for men as per the IDF criteria. The prevalence rates of AO are $60 \%$ and $86 \%$ for men and women respectively.

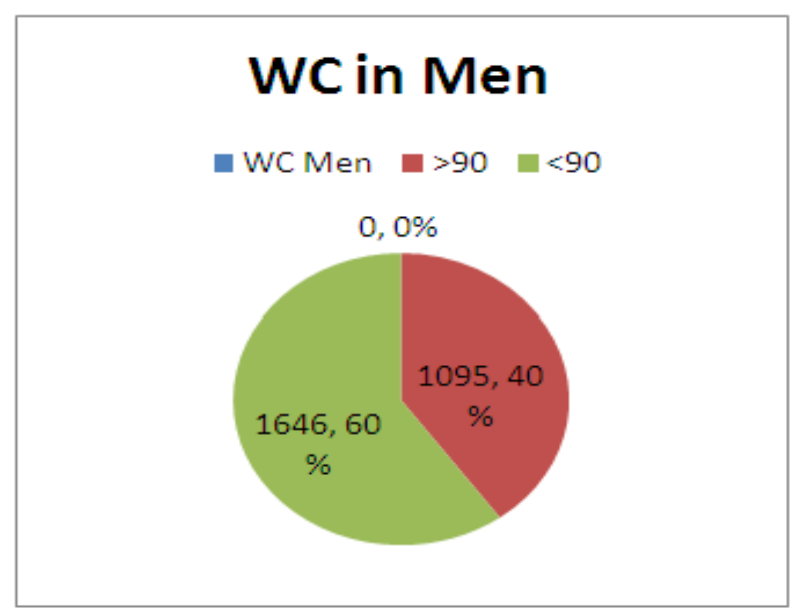

Figure-3

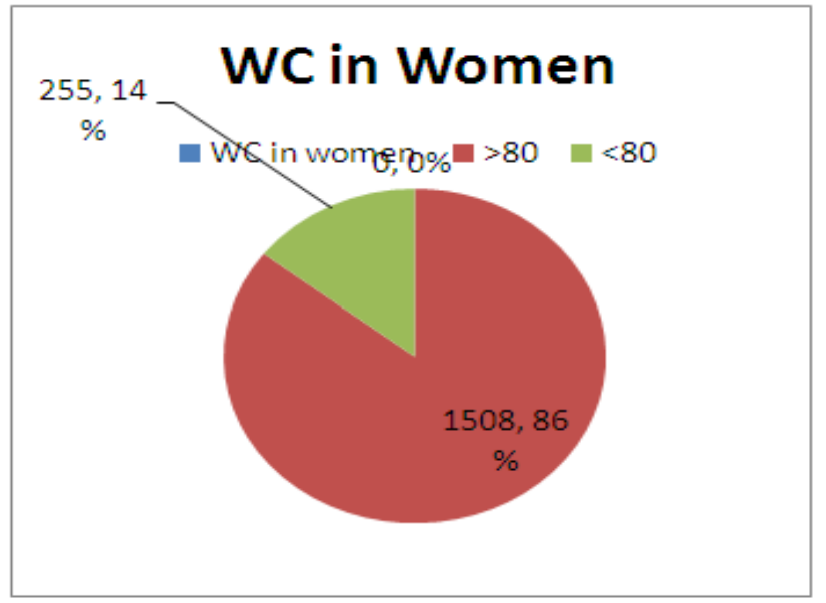

Figure-4 
In figure 5, using waist hip ratio as defined by WHO as a cut off for increased risk of metabolic complications as 0.9 and 0.85 for men and women respectively. We find that men have a raised WHR in $89 \%$ compared to $76 \%$ of women.

This identifies men with AO as a better index than measurement of a simple waist circumference. Though $86 \%$ of women have GO we find that $76 \%$ have $\mathrm{AO}$ according to WHR. In contrast, only $73 \%$ men had GO but $86 \%$ have AO as defined by WHR (fig-6).

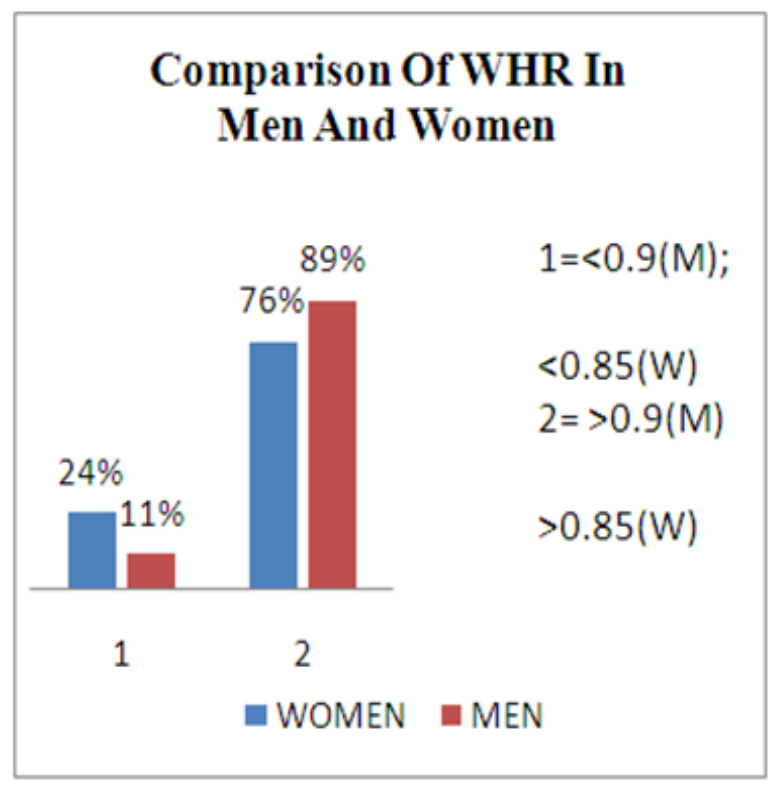

Figure-5

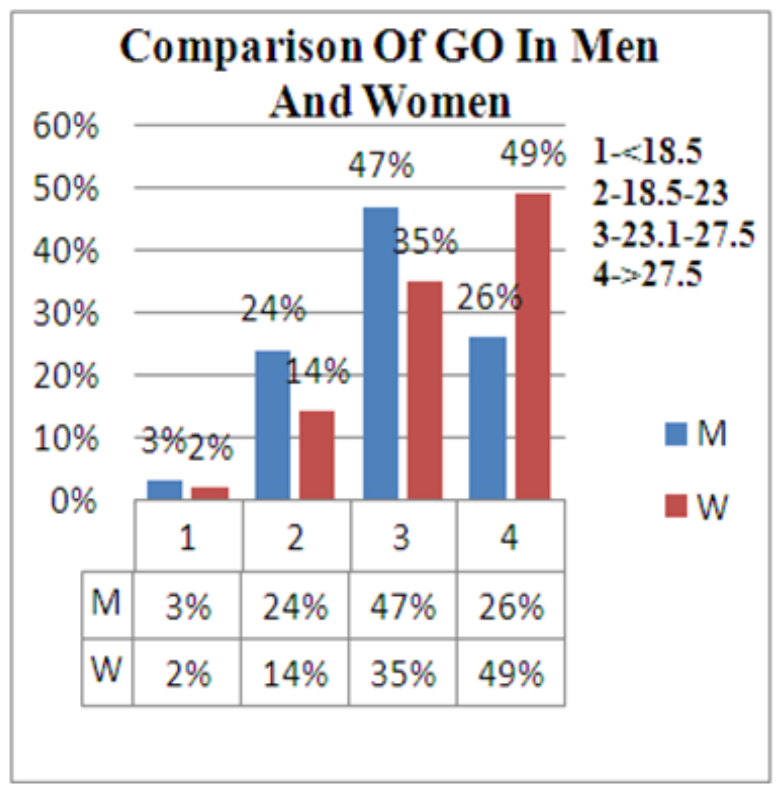

Figure-6

In figure 7 comparing all the three namely $\mathrm{GO}, \mathrm{AO}, \mathrm{CO}, \mathrm{IAO}, \mathrm{IGO}$ we find that the population has higher rates of $\mathrm{CO}$, $80 \%$ in women and $58 \%$ in men. IGO and IAO is $17 \%$ and $4 \%$ for men and $4 \%$ and $5 \%$ for women respectively.

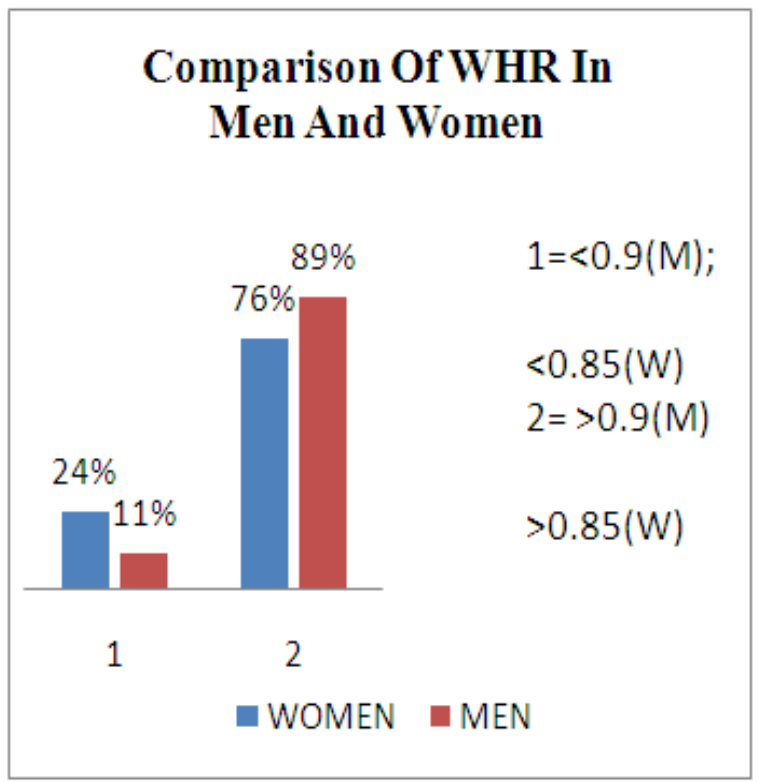

Figure-5

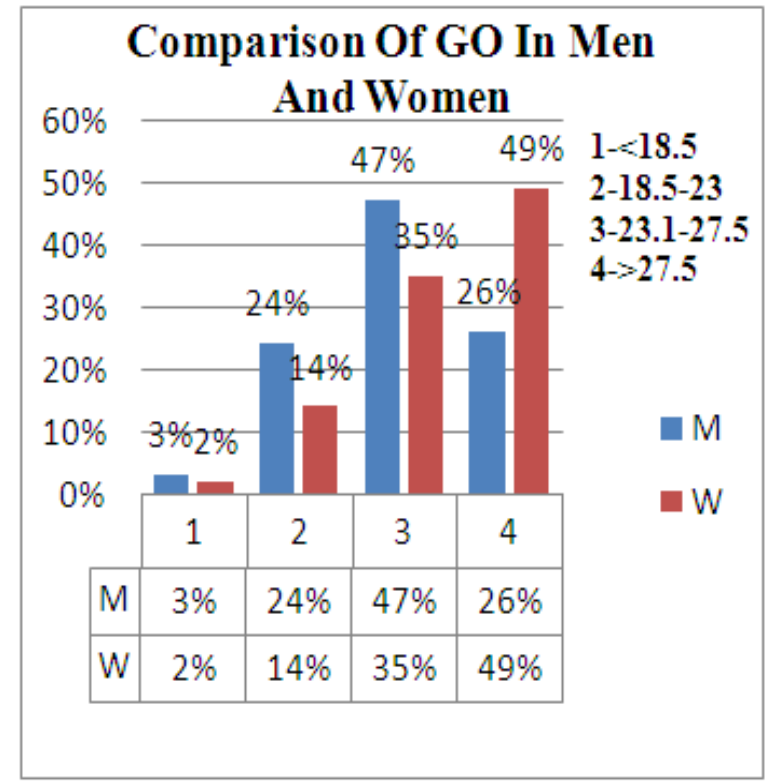

Figure-6

In figure 8 we can note the age incidence of diabetes in both genders to be similar, with both the lines in the graph overlapping each other. 


\section{Discussion}

In countries like India, the rapid increase in obesity prevalence could be attributed to the increasing urbanization, use of automotive transport, increasing availability of processed and fast foods, television viewing, adoption of less physically active lifestyles and consumption of more "energy-dense, nutrient-poor" diets [13-15]. This is exemplified by the higher prevalence of both $\mathrm{GO}$ and $\mathrm{AO}$ in the urban population where the above factors are more common.

Many studies have reported higher prevalence of obesity among women in different regions of India [1618]. In a study conducted in India among women aged 35-70 yr. the age-adjusted prevalence of obesity (BMI $\geq$ $25 \mathrm{~kg} / \mathrm{m} 2$ ) in urban and rural areas was 45.6 and 22.5 per cent, respectively [18]. A study by NFHS-3 group done in urban and rural subjects (women aged 15-49 and men aged 15-54) in 28 states of India, including Delhi during the year 2005-2006, showed a higher prevalence of women who were overweight (BMI $\geq 25$ $29.9 \mathrm{~kg} / \mathrm{m} 2)$ and obese $\left(B M I \geq 30 \mathrm{~kg} / \mathrm{m}^{2}\right)$ than males in different regions of India [17]. These studies were carried out in general population. Taking the diabetic population in our study we found that GO obesity was higher in women to the extent of $86 \%$ which is nearly twofold higher compared to general population.

Asian Indians have a higher predisposition to accumulation of visceral fat leading to abdominal obesity and this has been named as "Asian Indian phenotype [18-19]. Interestingly all studies so far have shown higher GO and $\mathrm{AO}$ in women, however we find that men too have higher AO than women using the WHR. This could be a sensitive index to identify men with $\mathrm{AO}$ as many studies have shown lower prevalence of $\mathrm{GO}$ and $\mathrm{AO}$ in the male population.

\section{Conclusion}

In summary, our study showed that prevalence of obesity (generalized and abdominal) was higher in women, and has increased to very high levels especially in the diabetic population now compared to earlier studies. Also, the significant finding was the prevalence of abdominal obesity was higher than the generalized obesity in men using the WHR thus making it a better index in measuring $A O$. We can expect further increase in the incidence and prevalence of obesity in India. Obesity, particularly in young women, can have unwanted consequences leading to infertility and development of polycystic ovary syndrome (PCOS), which can have significant effects on the risk of development of diabetes. Higher levels of obesity in young women are also worrisome because it may increase the risk of gestational diabetes, type 2 diabetes, hypertension and cardiovascular disease later in the life. This study is of significance because it shows large increases in prevalence of obesity in the diabetic population which can be extrapolated to the general population. With further urbanization, changing lifestyle and behaviour we may we may expect further increase in the incidence and prevalence of obesity in India.

Funding: Nil, Conflict of interest: None initiated, Permission from IRB: Yes

\section{References}

1. Source: Country statistics and global health estimates by WHO and UN partners http://www.who.int/gho/en /. http: //www.who/chp/chronic_disease_report/en

2. Flegal KM, Kit BK, Orpana H, Grau bard BI. Association of all-cause mortality with overweight and obesity using standard body mass index categories: a systematic review and meta-analysis. JAMA. 2013 Jan 2;309(1):71-82. doi: 10.1001/jama.2012.113905.

3. World Health Organization (WHO). Global health risks: 5. mortality and burden of disease attributable to selected major risks. Geneva: Switzerland, WHO; 2009. Available from: http://www.who.int/healthinfo/global_ burden_disease/GlobalHealthRisks_report_full.pdf, accessed on February 3, 2014.

4. Extract of the Global Diabetes Scorecard Tracking Progress for Action, International Diabetes Federation. www.idf.org/global-diabetes-scorecard.

5. Mohan V, Deepa R. Obesity and abdominal obesity in Asian Indians. Indian J Med Res. 2006 May; 123 (5):593-6.

6. Bhardwaj S, Misra A, Misra R, Goel K, Bhatt SP, Rastogi K, Vikram NK, Gulati S. High prevalence of abdominal, intra-abdominal and subcutaneous adiposity and clustering of risk factors among urban Asian Indians in North India. PLoS One. 2011;6(9): e24362. doi: 10.1371/journal.pone.0024362. Epub 2011 Sep 20. 
7. Misra A, Khurana L. Obesity and the metabolic syndrome in developing countries. J Clin Endocrinol Metab. 2008 Nov; 93 (11 Suppl 1): S9-30. doi: 10. 1210/jc. 2008-1595.

8. Anjana RM, Pradeepa R, Deepa M, Datta M, Sudha $\mathrm{V}$, Unnikrishnan $\mathrm{R}$, et al. The Indian Council of Medical Research-India Diabetes (ICMR - INDIAB) study: methodological details. J Diabetes Sci Technol 2011; 5: 906-14. J Diabetes Sci Technol. 2011 Jul; 5(4): 906-914. Published online 2011 Jul 1. PMCID: PMC 3192597.

9. The Asia Pacific perspective: redefining obesity and its treatment. Regional Office for the Western Pacific (WPRO), World Health Organization. International Association for the Study of Obesity and the International Obesity Task Force: St Leonards, Australia; Health Communications Australia Pty Limited; 2000. p. 22-9.

10. World Health Organization (WHO). International Diabetes Federation. Definition and diagnosis of diabetes mellitus and intermediate hyperglycaemia; report of a WHO/IDF consultation. Geneva: WHO; 2006.

11. Diet, nutrition and the prevention of chronic diseases. World Health Organ Tech Rep Ser. 2003;916: i-viii, 1-149, back cover.
12. Bell AC, Ge K, Popkin BM. The road to obesity or the path to prevention: motorized transportation and obesity in China. Obes Res. 2002 Apr;10(4):277-83.

13. Misra A, Singhal N, Khurana L. Obesity, the metabolic syndrome, and type 2 diabetes in developing countries: role of dietary fats and oils. J Am Coll Nutr. 2010 Jun; 29(3 Suppl):289S-301S.

14. Pandey RM, Gupta R, Misra A, Misra P, Singh V, Agrawal A, Dey S, Rao S, Menon VU, Kamalamma N, Devi KP, Revathi K, Sharma V. Determinants of urbanrural differences in cardiovascular risk factors in middle-aged women in India: a cross-sectional study. Int J Cardiol. 2013 Feb 20;163(2):157-62. doi: 10. 1016/j.ijcard.2011.06.008. Epub 2011 Aug 30.

15. Joshi SR. Metabolic syndrome--emerging clusters of the Indian phenotype. J Assoc Physicians India. 2003 May;51:445-6.

16. Mohan V, Sandeep S, Deepa R, Shah B, Varghese C. Epidemiology of type 2 diabetes: Indian scenario. Indian J Med Res. 2007 Mar;125(3):217-30.

17. Pettigrew R, Hamilton-Fairley D. Obesity and female reproductive function. Br Med Bull. 1997; 53 (2): 341-58.

\section{How to cite this article?}

Lalitha R, Surekha B Shetty, Anil Kumar R. The waistline of Indian men is expanding faster than women with general obesity and abdominal obesity reaching a epidemic in Indian subject with diabetes. Int J Med Res Rev 2016;4(10):18531858.doi:10.17511/ijmrr. 2016.i10.23. 